present volume. A good deal of it resembles an instrument dealer's catalogue, and almost every piece of apparatus used for zoological technique is described and figured. Then the choice of instruments and their use and abuse are considered, with many experienced remarks. The routine of zoological procedure, fixing, staining, mounting, the use of the microscope, and so on, are dealt with. There are many useful references to books or papers that advocate special methods.

The volume is intended for "Hochschulen" and universities, but there are one or two points in which its usefulness might have been increased. There are, for example, no instructions as to how to collect and observe animals. A few remarks on nets and boxes do not constitute instruction, and general directions would be a most useful addition, if they were devoted to skinning and preserving; how to work different kinds of ground, sea, lake, moor, \&c.; how to obtain material for observing life-histories. Another point omitted is the insertion of directions for collecting in other cauntries, especially in the tropics, where difficulties of unusual onder have to be overcome. Again, the author does not appear to describe how any of the apparatus may be made. It is, of course, nearly always possible to buy what you require ready-made, but there are many advantages in knowing how to make the simpler pieces of apparatus, since not only the manipulation is learnt, but the physics of the working are mastered in a way that no ready-made machine permits. For physiological work particularly such training is simply invaluable.

The only other point that has occurred to us is the incomplete nature of the instruction on certain modes of procedure, a drawback common to so many " practical" text-books. Thus in reconstructing embryos or animals from sections, the author does not state exactly what to do or what precautions to take to ensure a satisfactory result. Perhaps, however, the subject will recur in his later volume. In fact, any judgment on this section of the work is premature until the second part has appeared, as we trust it soon will. We must say, however, that only the beginner will learn much from the present instalment. The methods are, so far as we have been able to test them, well known and ably advocated already. But to anyone who is fitting up a laboratory or starting out upon a course of practical study, the work may be heartily recommended.

\section{CONSTRUCTION IN EARTHQUAKE COUNTRIES.}

Le Case Nelle Regioni Sismiche e la Scienza delle Costruzioni. By A. Montel. Pp. iv+ri6. (Torino : S. Lattes and Co., rgro.)

THIS book, dealing with construction in earthon the nature of earthquake motion, particularly acceleration. Then follows two scales of seismic intensity. After this a little is said about the nature of foundations, as, for example, whether they are upon soft or hard ground, on a slope, or on a plain. NO. 2 I 77 , VOL. 87]
The materials used for construction are given considerable consideration, particularly the advantages that may be obtained by the use of ferro-concrete. The pictures, like those showing the frameworly of buildings, and various formulæ are old acquaintances, whilst the text which accompanies them in many places closely follows a translation from English into Italian. Its author, Mr. Montel, particularly refers to two books from which he has obtained his information; one is No. 4 of the publications of the Earthquake Investigation Committee of Japan, written almost entirely by Dr. F. Omori, and the other is "La Science Séismologique," by Cornte de Montessus de Ballore. The other contributors to some eighty volumes issued by the Earthquake Investigation Committee have been omitted, and no reference made to the Transactions of the Seismological Society of Japan, in which we find accounts of almost everything that has been elaborated by Dr. Omori, and written about by Count Montessus and Mr. Montel.

Some thirty years ago, when Europeans were invited to Japan, their attention. was naturally directed to earthquakes. These they measured, and earthquake motion was for the first time reduced to mechanical units. The result was that engineers and constructors learned for the first time something about the forces with which they had to contend. The visitors even went a little further, and tested their suggested formulæ by placing columns of masonry and other articles on a truck which could be moved back and forth at an increasing rate. The quickness or suddenness of motion required to produce the shattering or overturning of these objects was recorded, and theory brought into closer relationship with practice. For many years past new forms of buildings have been rising in Japan, and these are found to withstand earthquake movement better than their predecessors. The formula of C. D. West, formerly professor of engineering in the University of Tokyo, which is the foundation of all other formulæ, relating to the more important principles guiding constructors occupies a prominent position in Mr. Montel's work, but the name of C. D. West is not mentioned. About this we need not be surprised, because it is only found with difficulty in those works from which he quotes. But practical seismology has grown and it must not be supposed that the guests who visited Japan some thirty years ago did everything. Their work also had foundations.

So far as we know, Robt. Mallet was practically the first man who treated earthqualke movement scientifically, and attempted to reduce it to practical units. Notwithstanding his work, engineers continued to regard an earthquake as something strong, and to resist its effects structures should be strong and heavy. Although M. Montel has not done all the justice he might have done by more extensive references, still he has produced a useful book, and if the principles it sets forth are adopted in the earthquakeshaken parts of Italy, they should do much to ameliorate the lot of inhabitants of those regions.

J. Milne. 